\title{
Real-World Glycemic Control from GLP-1RA Therapy with and Without Concurrent Insulin in Patients with Type 2 Diabetes
}

\author{
Mukul Singhal, PhD, BPh; Sudhir Unni, PhD; Marisa Schauerhamer, PharmD; Hiep Nguyen, MS; \\ Jeff Hurd, MS, PhD, MS; and Carrie McAdam-Marx, RPh, PhD
}

\begin{abstract}
BACKGROUND: Glucagon-like peptide 1 receptor agonists (GLP-1RAs) are recommended as add-on therapy in patients with uncontrolled type 2 diabetes (T2D), with no specific guidance as to timing versus insulin. Furthermore, real-world data assessing GLP-1RA outcomes with or without concurrent insulin therapy are lacking.
\end{abstract}

OBJECTIVE: To identify glycemic response with GLP-1RAs by insulin use in patients with T2D at 1-year follow-up to inform decisions regarding GLP1RA use with or without insulin.

METHODS: This uncontrolled retrospective cohort study included adults with T2D in the Quintiles Electronic Medical Records Database who were newly prescribed GLP-1RA therapy with exenatide once weekly or liraglutide once daily between February 1, 2012, and March 31, 2013 (index period). Primary outcomes were change in hemoglobin A1c (A1C) at 1 year and attainment of $A 1 C<7 \%,<8 \%$, and $<9 \%$. Results were stratified by baseline insulin use, which was defined as no insulin use at baseline, insulin initiated with a GLP-1RA on index date, and insulin prescribed before starting GLP-1RA therapy. Secondary outcomes included 1-year weight, lowdensity lipoprotein cholesterol (LDL-C), and blood pressure outcomes for the study population. Adjusted mean (marginal) change in A1c at 1 year was estimated using multivariate linear regression, and multivariate logistic regression was used to estimate the likelihood of patients attaining A1c $<7 \%$ at follow-up, controlling for potential confounders.

RESULTS: This study included 5,141 patients with a mean (SD) age of 57.0 (10.9) years, $53.5 \%$ of whom were females, and with a mean baseline A1C of $8.4 \%$ (1.6). Overall, $35.4 \%$ had no baseline insulin use, $42.9 \%$ were prescribed insulin before starting GLP-1RA therapy, and $21.7 \%$ were started on insulin with a GLP-1RA. The adjusted mean A1c reduction at 1 year was $0.75 \%(95 \% \mathrm{Cl}=-0.86$ to -0.63$)$ for patients initiating insulin on index date, $0.61 \%$ $(95 \% \mathrm{Cl}=-0.70$ to -0.51$)$ for patients with no baseline insulin use, and $0.23 \%$ $(95 \% \mathrm{Cl}=-0.33$ to -0.13$)$ for patients prescribed insulin before GLP-1RA therapy. Patients with no baseline insulin or who coinitiated insulin and a GLP-1RA were more likely to attain A1c $<7 \%$ at follow-up versus patients prescribed insulin before initiating GLP-1RA therapy $(0 R=1.50$, $95 \% \mathrm{Cl}=1.08$ to 2.09 and $\mathrm{OR}=1.85,95 \% \mathrm{Cl}=1.30$ to 2.62 , respectively). At 1-year follow-up, significant improvements in weight, LDL-C, and blood pressures were also observed.

CONCLUSIONS: GLP-1RA therapy was associated with significant improvements in glycemic control when used with or without insulin, as well as reductions in weight and LDL-C overall. However, greater A1c reductions and a higher likelihood of attaining A1c goal levels were observed when a GLP-1RA was initiated alone or with insulin than when a GLP-1RA was added to a regimen that included insulin. GLP-1RA therapy is an effective treatment option when used with or without insulin and may be considered in patients with uncontrolled glycemia.

J Manag Care Spec Pharm. 2017;23(3):267-75

Copyright $\odot 2017$, Academy of Managed Care Pharmacy. All rights reserved.

\section{What is already known about this subject}

Glucagon-like peptide 1 receptor agonists (GLP-1RAs) are effective in reducing hemoglobin Alc (Alc) and weight in the usual care setting.

A GLP-1RA and insulin combination is more efficacious at lowering Alc in patients with poorly controlled type 2 diabetes (T2D) than either agent alone as observed in clinical trials.

GLP-1RAs have been shown to improve some cardiovascular risk factors in patients with $\mathrm{T} 2 \mathrm{D}$

\section{What this study adds}

Patients with T2D started on a GLP-1RA alone or at the same time as insulin had greater Alc reduction and a higher likelihood of attaining Alc goal levels than patients who had a GLP-1RA added to a regimen that included insulin.

Alc reduction with GLP-1RA therapy alone or with insulin was most pronounced in patients with an Alc $\geq 9 \%$ at baseline, enabling more than $50 \%$ of these patients to achieve Alc of $<9 \%$ at 1-year follow-up.

Real-world evidence now exists that GLP-1RAs are associated with improvement in Alc, weight, low-density lipoprotein cholesterol, and blood pressure.

T ype 2 diabetes (T2D) is a chronic disorder responsible for significant morbidity, mortality, and economic burden in the United States. The estimated total cost of diabetes in 2012 was more than $\$ 245$ billion, including $\$ 176$ billion in direct medical costs. ${ }^{1}$ Diabetes-related complications are a significant driver of diabetes care costs and increase annual per-patient diabetes health care expenditures by approximately $\$ 10,000 .{ }^{2}$ Fortunately, effective management of hyperglycemia, as measured by reduction in hemoglobin Alc (Alc), can reduce the risk of diabetes-related microvascular and macrovascular complications. ${ }^{3}$

Given the clear trial-based evidence, payer and provider organizations recognized and adopted glycemic control targets based on Alc as a measure of diabetes care performance. For instance, the Healthcare Effectiveness Data and Information Set (HEDIS) comprehensive diabetes care measures include the proportion of patients in a diabetes population with poor glycemic control $(\mathrm{Alc}>9 \%){ }^{4}$ Consistent with treatment 
guidelines recommending individualized Alc targets, optimal Alc goal levels of $<7 \%$ and $<8 \%$ have also been incorporated into quality measures.

As a further incentive to improve diabetes outcomes and reduce costs, public and private payers are linking clinical performance vis-à-vis diabetes quality measures to provider reimbursement. $^{3}$ Since the passage of the Patient Protection and Affordable Care Act, there has been an expansion in the use of these pay-for-performance programs by private and public payers, particularly by Medicare and Medicaid. Specific to diabetes, the Centers for Medicare $\&$ Medicaid Services has established adequate glycemic control (Alc $<9 \%$ ) as a performance measure in the Quality Payment Program for Accountable Care Organizations and group practices, as well as in the Medicare Star Quality Rating System. ${ }^{3,5,6}$ Thus, attaining outcomes-based quality measures is a high priority for payers and providers.

Targeting patients with poorly controlled diabetes (Alc $\geq 9 \%$ ) for more aggressive drug therapy management is a potential approach health plans and providers could use to focus efforts and resources toward improving patient outcomes and achieving quality performance goals. For patients with poorly controlled diabetes, the American Diabetes Association and American College of Endocrinology/American Association of Clinical Endocrinologists guidelines recommend combination therapy, including regimens with insulin and/or a glucagonlike peptide 1 receptor agonist (GLP-1RA).,7

At the time of this study, the predominant agents in the GLP-1RA class were liraglutide once daily (QD) and exenatide once weekly $(\mathrm{QW})$. These agents have been shown in clinical trials to lower elevated Alc and are generally well tolerated. ${ }^{8}$ Unlike insulin, GLP-1RAs have relatively low rates of hypoglycemia and the added benefit of reducing weight. ${ }^{8-10}$ However, uncertainty remains regarding when to initiate a GLP-1RA relative to other agents, including insulin. Further, the real-world effectiveness of GLP-1RA drugs in patients with poor diabetes control is not well established.

The goal of this study was to obtain real-world evidence to inform payers and providers on the effectiveness of GLP-1RA therapy overall and in combination with baseline insulin. The objective of this study was, therefore, to identify the effect of GLP-1RAs on glycemic control quality targets (Alc $<7 \%,<8 \%$, and $<9 \%$ ) at 1 year stratified by baseline glycemic control status and concurrent insulin use. We also determined the impact of GLP-1RAs on weight change and other diabetes-related quality measures. ${ }^{4}$

\section{Methods}

\section{Study Design and Data Source}

A retrospective cohort study was conducted to assess 1-year treatment outcomes with GLP-1RA according to baseline insulin use in patients with T2D who initiated exenatide QW or liraglutide QD. This study used the Quintiles Electronic Medical
Records (Q-EMR) Database extending from January 1, 2011, through March 31, 2014. The Q-EMR is a large, centralized EMRbased data source containing data on 38 million patients provided by more than 725 member institutions and 33,000 providers from 49 U.S. states and the District of Columbia. The database includes patient-level demographic, diagnostic, laboratory, and vital sign data and is well suited to assess clinical outcomes in patients with T2D. The Investigational Review Board at the University of Utah approved the protocol for the study.

\section{Study Population}

Patients with T2D were identified in the database if they met at least 1 of the following inclusion criteria: an International Classification of Diseases, Ninth Revision, Clinical Modification code of $250 . x 0$ or $250 . x 2$; at least $1 \mathrm{Alc}$ value $>6.5 \%$; diabetes drug treatment; or 2 consecutive fasting blood glucose levels $\geq 126 \mathrm{mg} / \mathrm{dL}$. Patients selected from this T2D population for study inclusion were adults (aged 18+ years) newly prescribed with exenatide QW or liraglutide QD between February 1, 2012, and March 31, 2013. The T2D medications were identified at the class level from the prescription order and medication history data based on Generic Product Identifier ${ }^{11}$ therapeutic class designation. Index date was defined as the date of the first exenatide QW or liraglutide QD prescription order in the database.

Included patients had clinical activity in the EMR from at least 13 months before to 1 year after their index date, as well as Alc values on index date $(-60$ to +30 days $)$ and at 1-year follow-up ( \pm 60 days). Patients were excluded if they had documented use of a GLP-1RA in their medication history before index date, a diagnosis for type 1 diabetes or gestational diabetes, pregnancy, prescriptions for 2 or more GLP-1RAs on index date, or a switch to another GLP-1RA within 30 days after index date.

\section{Study Outcomes}

The primary outcome was glycemic control at 1 year, defined as change in Alc from baseline (index date) and proportion of patients with $\mathrm{Alc}<7 \%,<8 \%$, and $<9 \%$. Glycemic control outcomes were reported overall and stratified by baseline insulin use. Outcomes were defined as "no insulin prescribed during the baseline period," "insulin first prescribed with GLP-1RA on index date," or "insulin prescribed before index date." Glycemic outcomes were also reported in subsets of patients with baseline Alc $\geq 7 \%, \geq 8 \%$, and $\geq 9 \%$. Secondary outcomes reported for the overall cohort included changes in weight and low-density lipoprotein cholesterol (LDL-C) from baseline to 1-year follow-up, patients with follow-up LDL-C $<100 \mathrm{mg} / \mathrm{dL}$ and follow-up blood pressure $<140 / 90 \mathrm{mmHg}$ and <130/80 mmHg, per 2004 Seventh Joint National Committee and 2007 National Committee for Quality Assurance/HEDIS guidelines. ${ }^{4}$ 


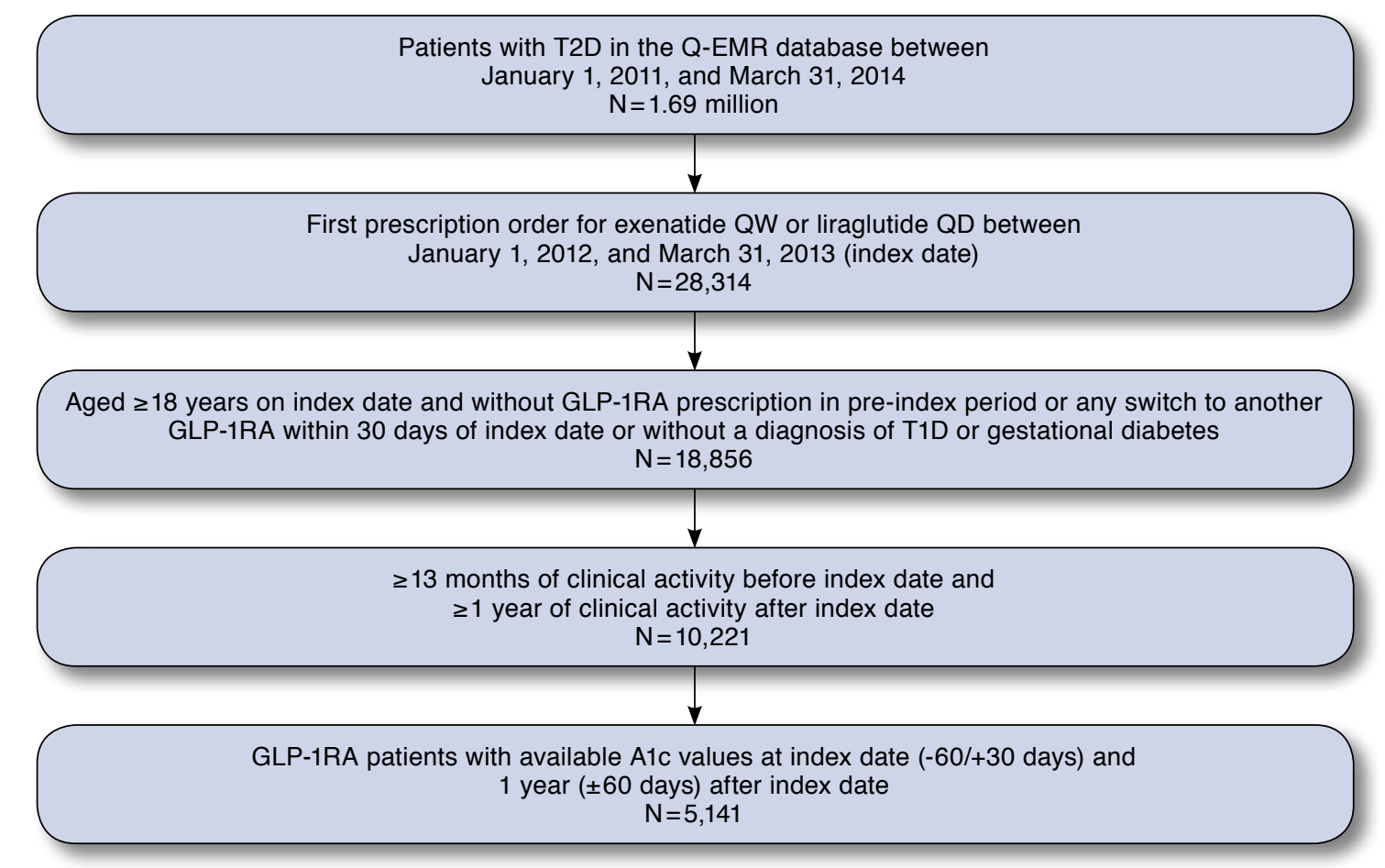

Alc=hemoglobin Alc; GLP-1RA=glucagon-like peptide 1 receptor agonist; QD = once daily; Q-EMR= Quintiles Electronic Medical Records; QW=once weekly; $T 1 D=$ type 1 diabetes; $T 2 D=$ type 2 diabetes.

\section{Independent Variables}

Demographic and clinical variables were captured to describe the study cohort and control for confounding factors. Demographic variables included age, sex, race, region, provider specialty, and insurance status; clinical covariates included baseline body mass index (BMI), blood pressure, comorbidities (hypertension, acute myocardial infarction, cardiovascular diseases [CVDs], cerebrovascular diseases, kidney disease, hyperlipidemia, and microvascular complications). The Charlson Comorbidity Index (CCI) was also calculated using the 2008 version designed to predict resource use in the primary care setting. The CCI was assessed as a method of adjusting for comorbidity in the analyses versus individual diabetes-related comorbidities. ${ }^{12,13}$ Non-GLP-1RA diabetes medication use during the 13-month baseline period and newly prescribed on index date was captured, as was the total number of diabetes medication classes used during the baseline period. Baseline antihypertensive use was also captured as a possible confounder.

\section{Statistical Analysis}

Descriptive statistics identified the baseline characteristics of the overall study population and by insulin use subgroups.
Independent t-test for continuous variables and chi-square test for categorical variables compared differences in baseline characteristics across the 3 insulin subgroups. A paired t-test compared the differences in Alc and weight from baseline to l-year follow-up overall and within insulin use groups; pairwise independent t-tests compared the change in Alc and weight between groups with insulin prescribed before index date considered as the reference group. Chi-square goodnessof-fit tests reported the change in the proportion of patients with Alc $<7 \%,<8 \%$, and $<9 \%$ at 1 -year follow-up overall and for subsets of patients with baseline Alc $\geq 7 \%, \geq 8 \%$, and $\geq 9 \%$.

Multivariate linear regression estimated the adjusted mean incremental change in Alc from baseline to follow-up by baseline insulin use. Multivariate logistic regression models identified the likelihood of patients attaining Alc $<7 \%$ at follow-up for those with baseline Alc $\geq 7 \%$ and separately for patients with baseline Alc $\geq 9 \%$. The saturated multivariate models controlled for baseline Alc, age, sex, race, region, insurance status, BMI, blood pressure, provider specialty, comorbidities (hypertension, acute myocardial infarction, CVDs, cerebrovascular disease, kidney disease, hyperlipidemia), microvascular complications, the $\mathrm{CCI}$, as well as diabetes medication and antihypertensive medication use. Regression models also 


\begin{tabular}{|c|c|c|c|c|c|c|}
\hline \multirow[b]{2}{*}{ Variable } & \multirow[b]{2}{*}{$\begin{array}{c}\text { Overall } \\
(\mathrm{N}=5,141)\end{array}$} & \multicolumn{5}{|c|}{ Baseline Insulin Use } \\
\hline & & $\begin{array}{c}\text { Insulin Newly } \\
\text { Prescribed on } \\
\text { Index Date } \\
(\mathrm{n}=1,115)\end{array}$ & $\begin{array}{l}\text { No Baseline } \\
\text { Insulin } \\
(\mathbf{n}=1,822)\end{array}$ & $\begin{array}{c}\text { Insulin } \\
\text { Prescribed } \\
\text { Pre-index } \\
(\mathrm{n}=2,204)\end{array}$ & $P$ Value ${ }^{a}$ & $P$ Value $^{b}$ \\
\hline Mean (SD) age, years & $57.0(10.9)$ & $56.2(11.3)$ & $56.9(10.8)$ & $57.5(10.8)$ & 0.001 & 0.079 \\
\hline Female (\%) & 53.5 & 56.1 & 52.6 & 53.1 & 0.105 & 0.749 \\
\hline \multicolumn{7}{|l|}{ Race (\%) } \\
\hline White & 70.3 & 69.6 & 73.6 & 67.9 & \multirow{5}{*}{0.648} & \multirow{5}{*}{0.003} \\
\hline Black & 7.3 & 6.7 & 6.9 & 7.9 & & \\
\hline Hispanic & 4.0 & 4.6 & 3.3 & 4.4 & & \\
\hline Other & 2.8 & 3.2 & 2.4 & 2.9 & & \\
\hline Unknown & 15.6 & 15.9 & 13.8 & 16.9 & & \\
\hline \multicolumn{7}{|l|}{ Insurance status (\%) } \\
\hline Commercial & 31.9 & 36.4 & 32.1 & 29.5 & \multirow{5}{*}{$<0.001$} & \multirow{5}{*}{0.003} \\
\hline Medicare & 26.0 & 23.9 & 23.9 & 28.9 & & \\
\hline Medicaid & 0.9 & 0.5 & 0.9 & 1.1 & & \\
\hline Self-pay & 1.1 & 0.7 & 1.6 & 0.9 & & \\
\hline Other/unknown & 40.0 & 38.5 & 41.5 & 39.6 & & \\
\hline Mean (SD) baseline Alc (\%) & $8.4 \quad(1.6)$ & $8.2 \quad(1.6)$ & $8.2 \quad(1.5)$ & $8.6 \quad(1.6)$ & $<0.001$ & $<0.001$ \\
\hline Mean (SD) baseline weight $(\mathrm{kg})$ & $108.0(24.8)$ & $107.7(25.0)$ & $106.9(24.7)$ & $109.3(24.6)$ & 0.078 & 0.002 \\
\hline Baseline blood pressure < 140/90 mmHg (\%) & 73.6 & 72.7 & 72.7 & 74.8 & 0.197 & 0.132 \\
\hline Baseline LDL-C $<100 \mathrm{mg} / \mathrm{dL}(\%)^{\mathrm{c}}$ & 66.2 & 65.9 & 65.3 & 67.1 & 0.639 & 0.423 \\
\hline Antihypertensive drugs (\%) & 83.6 & 81.7 & 84.5 & 83.8 & 0.136 & 0.540 \\
\hline \multicolumn{7}{|l|}{ Comorbidities (\%) } \\
\hline Hypertension & 73.0 & 72.3 & 74.2 & 72.4 & 0.960 & 0.191 \\
\hline Hyperlipidemia & 83.1 & 84.3 & 81.8 & 83.6 & 0.590 & 0.145 \\
\hline Kidney disease & 10.3 & 10.2 & 8.3 & 11.9 & 0.143 & $<0.001$ \\
\hline Cardiovascular disease & 8.3 & 7.3 & 7.6 & 9.3 & 0.044 & 0.053 \\
\hline Microvascular complications & 7.6 & 6.9 & 7.1 & 8.3 & 0.145 & 0.135 \\
\hline Cerebrovascular disease & 2.3 & 1.7 & 2.7 & 2.4 & 0.218 & 0.505 \\
\hline Acute myocardial infarction & 0.6 & 0.4 & 0.4 & 0.8 & 0.125 & 0.137 \\
\hline \multicolumn{7}{|c|}{$\begin{array}{l}\text { aP value indicating significant difference between insulin prescribed before index date versus insulin newly prescribed on index date. } \\
\text { bP value indicating significant difference between insulin prescribed before index date versus insulin not prescribed on or before index date. } \\
\text { cLDL-C values were available in } 1,734 \text { out of } 5,141 \text { overall patients, } 397 \text { patients with insulin newly prescribed on index date, } 680 \text { patients with insulin not prescribed on } \\
\text { or before index date, and } 657 \text { patients with insulin first prescribed on index date. } \\
\text { Alc=hemoglobin Alc; LDL-C =low-density lipoprotein cholesterol; } S D=\text { standard deviation. }\end{array}$} \\
\hline
\end{tabular}

controlled for insulin use on or up to 13 months before index date. Final, reduced models included covariates that contributed significantly to the model $(P>0.20)$ or in which there was a strong clinical rational for inclusion as a possible confounder. Stata software package 13 (StataCorp, College Station, TX) and SAS software package 9.3 (SAS Institute, Cary, NC) were used to perform all statistical analysis with an a priori alpha of 0.05 .

\section{Results}

\section{Baseline Characteristics}

Of the 1.69 million patients with diabetes in the Q-EMR database from January 1, 2011, to March 31, 2014, 5,141 patients met all inclusion criteria and were included in the final study cohort (Figure 1). Table 1 shows the demographic and clinical characteristics of the study cohort. Mean age (standard deviation [SD]) for the overall study cohort was 57.0 (10.9) years; $53.5 \%$ were female, and the majority $(70.3 \%)$ were white. Mean baseline Alc for the overall study cohort was 8.4\% (1.6). Overall, $35.4 \%$ of patients had no insulin prescriptions during the baseline period, $42.9 \%$ of patients were prescribed insulin before index date, and $21.7 \%$ of patients were first prescribed insulin on index date.

Table 1 also reports baseline characteristics stratified by baseline insulin use. Mean age was 57.5 (10.8) years for patients with an insulin prescribed before index date versus 56.9 (10.8) years for those with no insulin prescriptions during the baseline period $(P=0.079)$ and $56.2(11.3)$ years for patients first prescribed insulin along with the GLP-1RA on index date $(P=0.001)$. Baseline Alc was higher in patients with previous insulin use at $8.6 \%$ (1.6) versus $8.2 \%$ (1.5) in those with 


\begin{tabular}{|c|c|c|c|c|c|c|c|}
\hline & \multicolumn{4}{|c|}{ Baseline Alc, \% } & \multicolumn{3}{|c|}{ Baseline Insulin Use } \\
\hline & $\begin{array}{c}\text { Overall } \\
(n=5,141)\end{array}$ & $\begin{array}{c}\text { Alc } \geq 7 \% \\
(n=4,268)\end{array}$ & $\begin{array}{c}\text { Alc } \geq 8 \% \\
(n=2,804)\end{array}$ & $\begin{array}{c}\text { Alc } \geq 9 \% \\
(n=1,535)\end{array}$ & $\begin{array}{c}\text { Newly } \\
\text { Prescribed on } \\
\text { Index Date } \\
(\mathrm{n}=1,115)\end{array}$ & $\begin{array}{l}\text { Not Prescribed } \\
\text { on or Before } \\
\text { Index Date } \\
(\mathbf{n}=1,822)\end{array}$ & $\begin{array}{c}\text { First Prescribed } \\
\text { Before Index } \\
\text { Date } \\
(\mathrm{n}=2,204)\end{array}$ \\
\hline Baseline mean (SD) Alc & $8.4 \quad(1.6)$ & $8.8 \quad(1.4)$ & $9.4 \quad(1.3)$ & $10.3(1.2)$ & $8.2 \quad(1.6)$ & $8.2 \quad(1.5)$ & $8.6 \quad(1.6)$ \\
\hline Follow-up mean (SD) Alc & $7.9 \quad(1.6)$ & $8.1 \quad(1.6)$ & $8.5 \quad(1.7)$ & $8.9 \quad(1.8)$ & $7.6 \quad(1.5)$ & $7.7 \quad(1.5)$ & $8.2 \quad(1.6)$ \\
\hline Mean difference (SD) & $\begin{array}{l}-0.5 \quad(1.5) \\
P<0.001\end{array}$ & $\begin{array}{l}-0.6 \quad(1.6) \\
P<0.001\end{array}$ & $\begin{array}{ll}-0.9 & (1.7) \\
P<0.001\end{array}$ & $\begin{array}{l}-1.4 \quad(1.9) \\
P<0.001\end{array}$ & $\begin{array}{ll}-0.6 \quad(1.5) \\
P<0.001\end{array}$ & $\begin{array}{ll}-0.5 & (1.5) \\
P<0.001\end{array}$ & $\begin{array}{l}-0.4 \quad(1.6) \\
P<0.001\end{array}$ \\
\hline \multicolumn{8}{|l|}{ Alc goal attainment, ${ }^{a}$ n (\%) } \\
\hline$<7 \%$ & $1,581(30.7)$ & $979(22.9)$ & $437(15.6)$ & $190(12.4)$ & - & - & - \\
\hline$<8 \%$ & $3,082(59.9)$ & $2,284(53.5)$ & $1,191(42.5)$ & $513(33.4)$ & - & - & - \\
\hline$<9 \%$ & $4,069(79.1)$ & $3,225(75.6)$ & $1,885(67.2)$ & $869(56.6)$ & - & - & - \\
\hline
\end{tabular}

no baseline insulin use $(P<0.001)$ and versus $8.2 \%(1.6)$ in patients first prescribed insulin on index date $(P<0.001)$.

\section{Glycemic Control Outcomes}

The overall mean (SD) Alc reduction from baseline to 1-year follow-up was $0.5 \%$ (1.5). The proportion of patients with Alc below glycemic control quality targets of $<7 \%,<8 \%$, and $<9 \%$ improved at 1 year for all target levels $(P<0.001$ for all; Table 2$)$.

According to baseline insulin use, the mean Alc reduction from baseline to 1-year follow-up was $0.4 \%$ (1.6) in patients with insulin prescribed before index date, $0.5 \%$ (1.5) in those with no baseline insulin use, and $0.6 \%(1.5)$ in patients first prescribed insulin on index date $(P<0.001$ for Alc change, all groups; Table 2). The proportion of patients attaining Alc $<7 \%$ by baseline insulin use is presented in Figure 2. The proportion of patients attaining Alc goal was higher at followup than baseline $(P<0.001$ for all groups), with the proportions tending to be lower for patients prescribed insulin before index date (23.9\% vs. $37.7 \%$ and $34.8 \%)$.

Among patients with baseline Alc $\geq 9 \%$, there were 476 patients without insulin prescription on or before index date, 312 patients prescribed insulin on index date, and 747 patients prescribed insulin before index date. A higher proportion of patients on GLP-1RA who were not prescribed insulin on or before index date were able to reach goal versus the group of patients who were coprescribed insulin and GLPIRA and patients who were prescribed insulin before index date, respectively (63.2\% vs. $57.7 \%$ and $51.9 \%$ ).

Glycemic control outcomes were also evaluated in subsets of patients with baseline Alc $\geq 7 \%, \geq 8 \%$, and $\geq 9 \%$, regardless of baseline insulin use (Table 2). In patients with a baseline Alc $\geq 7 \%$, mean Alc reduction was $0.6 \%$ (1.6) from a baseline of $8.8 \%$ (1.4). In those with baseline $\mathrm{Alc} \geq 8 \%$, mean Alc reduction was $0.9 \%$ (1.7) from a baseline of $9.4 \%$ (1.3), and mean Alc reduction was $1.4 \%$ (1.9) from a baseline of $10.3 \%$ (1.2) in those with a baseline Alc $\geq 9 \%$ ( $P<0.001$ for all groups).
Multivariate regression analyses were conducted to identify the association between baseline insulin use and glycemic control with GLP-1RA therapy, with the final, reduced models controlling for age, sex, race, region, provider specialty, baseline Alc, diabetes-related comorbidities, and diabetes medication use before index date. The linear regression model (Table 3) indicated that patients with no baseline insulin use had a greater Alc reduction than patients prescribed insulin before index date (coefficient $-0.38 ; 95 \%$ confidence interval $[C I]=-0.55$ to $-0.21 ; P=0.001$ ), as did patients who were newly initiated on insulin on index date (coefficient -0.52 ; $95 \% \mathrm{CI}=-0.70$ to $-0.34 ; P<0.001)$. Furthermore, each $1 \%$ increase in baseline Alc was associated with a $0.5 \%$ greater reduction in Alc from baseline to 1-year follow-up (coefficient $-0.51 ; 95 \% \mathrm{CI}=-0.48$ to $-0.52 ; P<0.001$ ).

Patients aged $\geq 65$ years, females, or having a GLP-1RA prescribed by an endocrinologist had a higher Alc reduction relative to patients aged $<40$ years, males, and having a GLPIRA prescribed by a primary care provider. Further, patients with baseline CVD or with a sulfonylurea prescribed before index date had an increase in Alc relative to those without CVD or who had no use of a sulfonylurea in the baseline period $(P<0.05$ for all; Table 3$)$. When setting the model covariates to the population mean or most common categorical value, the adjusted (marginal) mean Alc reduction at follow-up was $0.75 \%$ (95\% CI $=-0.86$ to -0.63$)$ for patients with insulin first prescribed on index date with a GLP-1RA, 0.61\% (95\% $\mathrm{CI}=-0.70$ to -0.51 ) for patients with no baseline insulin use, and $0.23 \%$ (95\% CI $=-0.33$ to -0.13$)$ for patients prescribed insulin before index date (data not shown).

In multivariate logistic regression analyses controlling for potential confounders as listed above (Table 3 and Appendix A, available in online article), patients with no baseline insulin use were more likely to attain Alc $<7 \%$ at follow-up compared with patients prescribed insulin before index date (odds 


\section{FIGURE 2 Proportion of Patients with A1c Goal Attainment (Alc <7\%) at 1-Year Follow-Up} by Insulin Use at Baseline

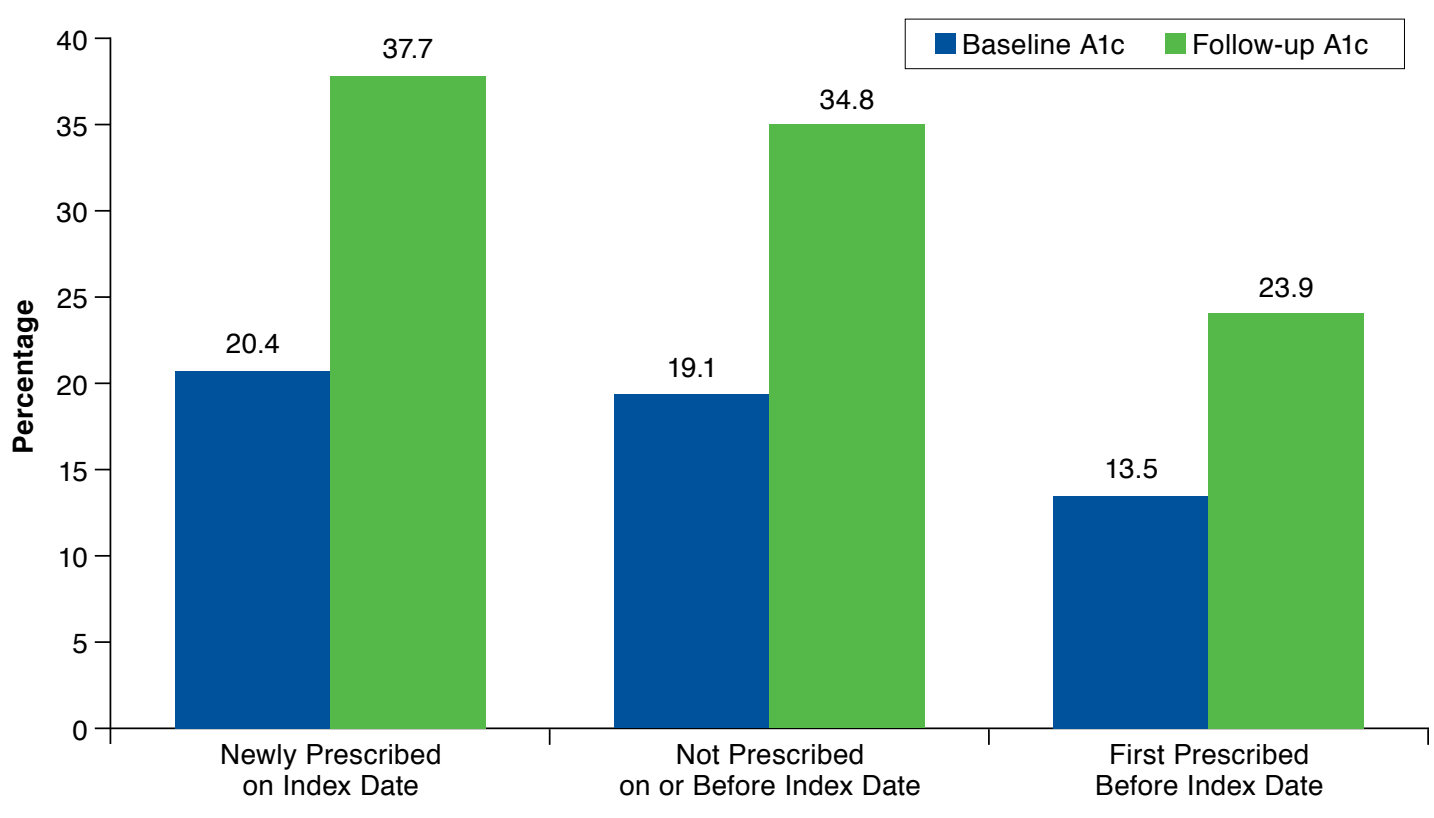

Note: $P<0.001$ for percentage of patients with Alc $<7 \%$ at 1-year follow-up versus baseline for all 3 groups. Alc $=$ hemoglobin Alc

ratio $[\mathrm{OR}]=1.50,95 \% \mathrm{CI}=1.08$ to $2.09, P=0.015$ ), as were patients first prescribed insulin on index date with a GLP-1RA $(\mathrm{OR}=1.85,95 \% \mathrm{CI}=1.30$ to $2.62, \mathrm{P}=0.001)$. In addition, each $1 \%$ increase in baseline Alc reduced the likelihood of achieving follow-up Alc $<7 \%$ by $50 \%(\mathrm{OR}=0.50,95 \% \quad \mathrm{CI}=0.47$ to $0.54, \quad P<0.001), \quad A 1 c<8 \%$ by $53 \% \quad(\mathrm{OR}=0.53, \quad 95 \%$ $\mathrm{CI}=0.50$ to $0.56, P<0.001)$, and $\mathrm{Alc}<9 \%$ by $52 \%(\mathrm{OR}=0.52$, 95\% CI $=0.49$ to $0.55, P<0.001$ ).

Patients with a history of CVD were less likely to attain Alc $<7 \%$, whereas patients with baseline cerebrovascular disease were more likely to attain Alc $<7 \%$ ( $P<0.05$ for both). Additionally, sulfonylurea use in the past 13 months was associated with decreased likelihood of achieving Alc $<7 \%$ in patients with baseline Alc $\geq 7 \%(\mathrm{OR}=0.71,95 \% \mathrm{CI}=0.51$ to $0.97, P=0.034)$ and likewise, in patients with baseline Alc $\geq 9 \%$ $(\mathrm{OR}=0.69,95 \% \mathrm{CI}=0.50$ to $0.95, P=0.021$; Table 3$)$.

\section{Weight, LDL-C, and Blood Pressure Outcomes}

A significant mean (SD) weight reduction of $2.2(7.0) \mathrm{kg}$ $(P<0.001)$ from baseline to 1 -year follow-up was observed for the overall patient cohort. A small but statistically significant reduction in LDL-C was also observed (2.1 [30.5] $\mathrm{mg} / \mathrm{dL}, \quad P=0.003)$, while the percentage of patients with LDL-C $<100 \mathrm{mg} / \mathrm{dL}$ did not differ from baseline $(67.1 \%)$ to follow-up (69.2\%; $P=0.722)$. The percentage of patients with blood pressure $<140 / 90 \mathrm{mmHg}$ was greater at follow-up (76.5\%) than at baseline $(73.2 \% ; P<0.001)$ as was the percentage of patients with blood pressure $<130 / 80 \mathrm{mmHg}$ (42.2\% vs. 39.0\%; $P<0.001$; Appendix B, available in online article).

\section{Discussion}

This study demonstrated that patients with T2D treated in a real-world setting who initiated GLP-1RA therapy with exenatide QW or liraglutide QD had significantly improved glycemic control regardless of baseline insulin use. Further, for the subgroup of patients with poorly controlled diabetes (Alc $\geq 9 \%$ ), the reduction in Alc was relatively higher compared with patients with $\mathrm{Alc} \geq 7 \%$. In addition to Alc reduction, clinical risk factors also improved as measured by weight reduction and achievement of comprehensive diabetes quality metrics for Alc, blood pressure, and LDL-C.

A key study finding showed the observed reduction in Alc was significant regardless of baseline insulin use. Patients with no prior insulin use were more likely to achieve glycemic goal with a GLP-1RA compared with patients who started insulin before initiating GLP-1RA treatment. This finding is likely due in part to higher baseline Alc in these patients, suggesting that prior insulin users may have had more disease progression and/or poorer adherence to medications and lifestyle recommendations. Patients who had the highest response to 
TABLE 3 Multivariate Linear Regression for Change in Alc from Baseline to 1-Year Follow-up, and Logistic Regression for Patients Reaching Alc Goal< $7 \%$ at 1 Year for Patients with Baseline Alc $\geq 7 \%$ and $\geq 9 \%$

\begin{tabular}{|c|c|c|c|c|c|c|c|c|c|}
\hline \multirow[b]{3}{*}{ Variable } & \multirow{2}{*}{\multicolumn{3}{|c|}{$\begin{array}{c}\text { Linear Regression } \\
(\mathrm{N}=4,321)\end{array}$}} & \multicolumn{6}{|c|}{ Logistic Regression } \\
\hline & & & & \multicolumn{3}{|c|}{ Baseline Alc $\geq 7 \%(n=4,319)$} & \multicolumn{3}{|c|}{ Baseline Alc $\geq 9 \%(n=1,285)$} \\
\hline & Coef & $95 \% \mathrm{CI}$ & $P$ Value & Odds Ratio & $95 \% \mathrm{CI}$ & $P$ Value & Odds Ratio & $95 \% \mathrm{CI}$ & $P$ Value \\
\hline Baseline Alc (\%) & -0.51 & -0.48 to -0.53 & $<0.001$ & 0.50 & 0.47 to 0.54 & $<0.001$ & 0.87 & 0.75 to 1.02 & 0.080 \\
\hline \multicolumn{10}{|c|}{ Baseline insulin use (ref: insulin prescribed before index date) } \\
\hline $\begin{array}{l}\text { Not prescribed on } \\
\text { or before index date }\end{array}$ & -0.38 & -0.55 to -0.21 & 0.001 & 1.50 & 1.08 to 2.09 & 0.015 & 2.21 & 0.89 to 5.49 & 0.088 \\
\hline $\begin{array}{l}\text { Newly prescribed } \\
\text { on index date }\end{array}$ & -0.52 & -0.70 to -0.34 & $<0.001$ & 1.85 & 1.30 to 2.62 & 0.001 & 2.36 & 0.95 to 5.85 & 0.065 \\
\hline \multicolumn{10}{|l|}{ Age, years (reference: $<40$ ) } \\
\hline $40-64$ & -0.09 & -0.26 to 0.08 & 0.294 & 0.96 & 0.70 to 1.32 & 0.809 & 1.33 & 0.97 to 1.83 & 0.076 \\
\hline$\geq 65$ & -0.23 & -0.42 to -0.04 & 0.019 & 1.04 & 0.73 to 1.48 & 0.841 & 1.77 & 1.21 to 2.59 & 0.003 \\
\hline Female & -0.10 & -0.19 to -0.02 & 0.017 & 1.17 & 1.00 to 1.36 & 0.045 & 1.18 & 0.99 to 1.40 & 0.059 \\
\hline \multicolumn{10}{|l|}{ Race (reference: white) } \\
\hline African-American & & & & 0.68 & 0.50 to 0.92 & 0.013 & 1.10 & 0.80 to 1.51 & 0.560 \\
\hline Hispanic & & & & 0.93 & 0.63 to 1.37 & 0.725 & 0.69 & 0.46 to 1.05 & 0.081 \\
\hline Other & & & & 0.70 & 0.44 to 1.13 & 0.149 & 0.88 & 0.53 to 1.44 & 0.605 \\
\hline \multicolumn{10}{|l|}{ Region (reference: East) } \\
\hline South & -0.22 & -0.33 to -0.12 & $<0.001$ & 1.48 & 1.22 to 1.79 & $<0.001$ & 1.16 & 0.94 to 1.43 & 0.176 \\
\hline Midwest & -0.23 & -0.35 to -0.10 & $<0.001$ & 1.31 & 1.04 to 1.65 & 0.024 & 1.26 & 0.97 to 1.63 & 0.079 \\
\hline West & -0.25 & -0.40 to -0.10 & $<0.001$ & 1.46 & 1.12 to 1.92 & 0.006 & 1.49 & 1.09 to 2.05 & 0.013 \\
\hline \multicolumn{10}{|c|}{ Provider specialty (reference: primary care) } \\
\hline Endocrinology & -0.10 & -0.19 to -0.01 & 0.030 & 1.02 & 0.87 to 1.21 & 0.776 & 1.26 & 1.04 to 1.53 & 0.019 \\
\hline Other & -0.30 & -1.01 to 0.41 & 0.410 & 1.24 & 0.33 to 4.58 & 0.749 & 2.01 & 0.41 to 9.90 & 0.390 \\
\hline \multicolumn{10}{|l|}{ Comorbidities } \\
\hline Hypertension & 0.00 & -0.10 to 0.10 & 0.999 & 1.00 & 0.83 to 1.20 & 0.994 & 0.97 & 0.79 to 1.21 & 0.808 \\
\hline Acute MI & 0.02 & -0.49 to 0.52 & 0.953 & 1.05 & 0.42 to 2.60 & 0.922 & 0.80 & 0.29 to 2.16 & 0.657 \\
\hline Cardiovascular disease & 0.15 & 0.00 to 0.31 & 0.046 & 0.71 & 0.54 to 0.95 & 0.020 & 0.74 & 0.55 to 1.01 & 0.054 \\
\hline Cerebrovascular disease & -0.28 & -0.60 to 0.05 & 0.096 & 1.78 & 1.01 to 3.12 & 0.045 & 1.60 & 0.76 to 3.34 & 0.214 \\
\hline Kidney disease & -0.01 & -0.15 to 0.13 & 0.895 & 1.02 & 0.78 to 1.33 & 0.897 & 0.99 & 0.73 to 1.32 & 0.922 \\
\hline Hyperlipidemia & 0.02 & -0.09 to 0.13 & 0.720 & 0.95 & 0.78 to 1.15 & 0.581 & 1.03 & 0.81 to 1.30 & 0.805 \\
\hline $\begin{array}{l}\text { Microvascular } \\
\text { complications }\end{array}$ & 0.08 & -0.08 to 0.24 & 0.315 & 0.74 & 0.55 to 1.00 & 0.050 & 0.83 & 0.61 to 1.13 & 0.231 \\
\hline \multicolumn{10}{|c|}{ Other diabetes medication classes prescribed prescribed before index date } \\
\hline Metformin & -0.02 & -0.20 to 0.16 & 0.814 & 1.19 & 0.84 to 1.67 & 0.329 & 0.95 & 0.68 to 1.34 & 0.773 \\
\hline Sulfonylurea & 0.29 & 0.12 to 0.45 & 0.001 & 0.71 & 0.51 to 0.97 & 0.034 & 0.69 & 0.50 to 0.95 & 0.021 \\
\hline TZDs & 0.13 & -0.04 to 0.30 & 0.143 & 0.95 & 0.68 to 1.33 & 0.769 & 0.78 & 0.56 to 1.07 & 0.127 \\
\hline DPP-4 & 0.08 & -0.08 to 0.24 & 0.337 & 0.89 & 0.64 to 1.22 & 0.465 & 0.96 & 0.71 to 1.31 & 0.818 \\
\hline Pramlintide & 0.16 & -0.24 to 0.57 & 0.429 & 1.32 & 0.63 to 2.80 & 0.463 & 0.69 & 0.33 to 1.46 & 0.333 \\
\hline Other OADs & 0.20 & -0.04 to 0.43 & 0.102 & 0.94 & 0.60 to 1.47 & 0.794 & 0.48 & 0.31 to 0.73 & 0.001 \\
\hline
\end{tabular}

GLP-1RA therapy were those who were prescribed both insulin and a GLP-1RA for the first time on index date, although the baseline Alc in this insulin group was the same (8.2\%) as for those with no baseline insulin use. Thus, these data support a hypothesis that initiation of GLP-1RA therapy with or before insulin is an effective real-world treatment strategy.

The significant glycemic control and weight response with GLP-1RA therapy are consistent with clinical trial data. ${ }^{8}$ In a pivotal head-to-head trial, ${ }^{8}$ patients on exenatide $\mathrm{QW}$ or liraglutide QD for 6 months had a least square mean (SE) Alc reduction of $1.28 \%(0.05)$ and $1.48 \%(-0.05)$, respectively, and $60 \%$ of liraglutide QD patients and $53 \%$ of exenatide QW patients achieved Alc $<7 \%$ during the follow-up. The least square mean weight reduction in patients with exenatide QW and liraglutide QD in these clinical trials ranged from $2.68(0.18) \mathrm{kg}$ to $3.57(0.18) \mathrm{kg}$, with no severe hypoglycemic events reported. 
In observing reductions in Alc overall, the present study contributes to the real-world evidence regarding the effectiveness of GLP-1RAs. While the effect is consistent, the magnitude of Alc reduction in this study was less than observed in clinical trials. This study followed patients initiated on GLP-1RA therapy for 1 year and identified a mean Alc reduction of $50 \%$ (1.5), and $30.7 \%$ of patients achieved Alc $<7 \%$ at followup. The smaller Alc reduction observed in this study relative to clinical trials likely reflects the real-world setting where monitoring and treatment are not as regimented and consistent, and adherence to medication therapy and lifestyle recommendations may be lower. Additionally, the clinical trial included slightly more male patients than our study, was predominantly white, and was restricted to patients with active cardiac diseases and other comorbidities, whereas our real-world study did not exclude patients based on comorbidities.

This study also provides real-world evidence that patients with poorly controlled diabetes can have significant Alc reduction with GLP-1RA therapy. In a clinical trial with a subgroup of patients with Alc $\geq 9 \%$ and a follow-up of 6 months, Buse et al. $(2013)^{8}$ found a least square mean Alc reduction of $1.75 \%$ (0.09) and 2.04\% (0.09) in exenatide and liraglutide groups, respectively. In our study, patients with $A 1 c \geq 9 \%$ prescribed exenatide QW or liraglutide QD had a mean Alc reduction of $1.4 \%$ (1.9) at 1-year follow-up, and $56.6 \%$ of patients had Alc $<9 \%$. While this improvement in glycemic control was significant and clinically meaningful, the proportion of these patients who were able to attain Alc $<7 \%$ was $12.4 \%$, which likely reflects their high starting Alc (10.3\%) and the challenges in achieving such dramatic reduction in Alc.

Given the high cardiovascular (CV) comorbidities with T2D, the ideal diabetes therapy should improve glycemic control and other CV risk factor markers. Data from this study suggest that GLP-1RAs used with or without concomitant insulin have benefits on CV risk factors, including weight, blood pressure, and LDL-C, which is consistent with previous findings. ${ }^{14-16}$ However, as secondary outcomes, weight, LDL-C, and blood pressure results were not adjusted for confounders, including concomitant therapy for hypertension and hyperlipidemia. Thus, these findings should be interpreted with caution, and future research assessing CV risk factor outcomes with GLPIRA therapy in the real-world setting is warranted. Further, we only assessed these CV-related outcomes in the overall study population and did not identify if these outcomes were also observed in subsets of patients by baseline glycemic control or insulin use.

Sulfonylurea use during the 13 months before index date was associated with a decreased likelihood of attaining Alc goals in patients with Alc $\geq 7 \%$ and $\geq 9 \%$, respectively (Table 3). This interesting finding could possibly be due to these patients being older with higher disease progression and with a less stringent Alc goal. These findings were observed in a subgroup analysis where sulfonylurea use was higher in patients $\geq 65$ years (30\% vs. $26 \%$ in patients $<65$ years) as well as in patients with $\geq 3$ antidiabetes drugs, where $75 \%$ of these patients were on a sulfonylurea (data not shown).

\section{Limitations}

While this study is the first to our knowledge to assess realworld GLP-1RA treatment outcomes according to patterns of insulin use, a number of limitations should be highlighted. First, this study was limited to assessing the outcomes associated with liraglutide QD and exenatide QW, as they were the predominant GLP-1RAs at the time of the study. Thus, the result may not be generalizable to newer GLP-1RAs, including albiglutide, dulaglutide, and lixisenatide. Also, the study did not control for patients who may have switched between the GLP-1RA medications after 30 days or had a change in index insulin prescription status.

Further, requirements that patients have a minimum duration of activity in the dataset and Alc data to assess outcomes may have introduced additional selection bias. Namely, included patients may have better continuity of care, followup, and monitoring than patients not meeting study inclusion criteria. We used prescription orders to capture the medication use, which may have introduced misclassification bias Prescription orders indicate that a physician prescribed a medication, but orders do not provide information on whether the patient obtained the medication and then took it as prescribed.

In addition, this study used a pre-post design for assessing patient outcomes and did not include a non-GLP-1RA control group. Further, outcomes were only assessed at 1 year and not at interim periods, such as 3 and 6 months. Finally, research using administrative datasets is limited by the lack of data to control for other factors and patient behaviors that can affect outcomes, such as adherence to diet and exercise.

\section{Conclusions}

GLP-1RA therapy, alone or in combination with insulin, is effective in improving Alc and weight in patients with T2D in the real-world setting, which translates to improvement in quality measures. Patients treated with a GLP-1RA who were not prescribed insulin during the baseline period or on index date and patients who initiated insulin on index date had greater Alc reductions than patients who were prescribed insulin during the baseline period and before initiating GLP-1RA therapy. Further, patients with Alc $\geq 9 \%$ responded notably well to GLP-1RA therapy, supporting GLP-1RAs as another option for patients with Alc $\geq 9 \%$, particularly if weight loss and hypoglycemia avoidance are treatment goals. Given these outcomes, use of GLP-1RAs is also effective in helping provider and payer organizations improve diabetes-related outcomes and performance measures. 


\section{Authors}

MUKUL SINGHAL, PhD, BPh; MARISA SCHAUERHAMER, PharmD; and CARRIE McADAM-MARX, RPh, PhD, Department of Pharmacotherapy and Pharmacotherapy Outcomes Research Center, University of Utah, Salt Lake City. SUDHIR UNNI, PhD, Pharmacotherapy Outcomes Research Center, University of Utah, Salt Lake City. HIEP NGUYEN, MS, and JEFF HURD, MS, PhD, MS, AstraZeneca, Fort Washington, Pennsylvania.

AUTHOR CORRESPONDENCE: Carrie McAdam-Marx, RPh, PhD, Pharmacotherapy Outcomes Research Center, University of Utah, 30 S. 2000 E., Rm. 4980, Salt Lake City, UT 84112.

Tel.: 801.587.9639; E-mail: Carrie.mcadam-marx@pharm.utah.edu.

\section{DISCLOSURES}

The study was funded by a collaborative research grant from AstraZeneca. Employees of AstraZeneca participated in most aspects of the study and in manuscript preparation. Nguyen and Hurd are employed by, and hold stock in, AstraZeneca. McAdam-Marx reports participation in the AMCP Diabetes Partnership and has stock ownership in GlaxoSmithKline.

Study concept and design were contributed by Nguyen, McAdam-Marx, and Singhal, along with Unni and Schauerhamer. Singhal, Unni, Nguyen, and McAdam-Marx collected the data, with assistance from Schauerhamer and Hurd, and data interpretation was performed by Unni, Hurd, McAdamMarx, Singhal, Nguyen, and Schauerhamer. The manuscript was written by Singhal, Schauerhamer, Unni, and McAdam-Marx, along with Nguyen and Hurd, and revised by McAdam-Marx, Singhal, Unni, and Nguyen, along with Schauerhamer and Hurd.

\section{REFERENCES}

1. American Diabetes Association. Economic costs of diabetes in the U.S. in 2012. Diabetes Care. 2013;36(4):1033-46.

2. Vojta D, De Sa J, Prospect T, Stevens S. Effective interventions for stemming the growing crisis of diabetes and prediabetes: a national payer's perspective. Health Aff (Millwood). 2012;31(1):20-26.

3. American Diabetes Association. 2016 standards of medical care in diabetes. Diabetes Care. 2016;39(Supplement 1):S1-2.
4. National Committee for Quality Assurance. HEDIS 2009 Volume 2 technical update. Comprehensive diabetes care. October 1, 2008. Available at: http://www.ncqa.org/portals/0/PolicyUpdates/HEDIS\%20Technical\%20 Updates/09_CDC_Spec.pdf. Accessed January 25, 2017.

5. Centers for Medicare $\&$ Medicaid Services. Medicare shared savings program quality measure benchmarks for the 2015 reporting year. Available at: https://www.cms.gov/Medicare/Medicare-Fee-for-Service-Payment/sharedsavingsprogram/Downloads/MSSP-QM-Benchmarks-2015.pdf. Accessed January 16, 2017.

6. Centers for Medicare \& Medicaid Services. Quality payment program. 2016. Available at: https://www.cms.gov/Medicare/Quality-InitiativesPatient-Assessment-Instruments/Value-Based-Programs/MACRA-MIPSand-APMs/Quality-Payment-Program-MACRA-NPRM-Slides.pdf. Accessed January 16, 2017.

7. Garber AJ, Abrahamson MJ, Barzilay Jl, et al. AACE/ACE comprehensive diabetes management algorithm, 2015. Endocr Pract. 2015;21(4):438-47.

8. Buse JB, Nauck M, Forst T, et al. Exenatide once weekly versus liraglutide once daily in patients with type 2 diabetes (DURATION-6): a randomised, open-label study. Lancet. 2013;381(9861):117-24.

9. Blonde L, Pencek R, MacConell L. Association among weight change, glycemic control, and markers of cardiovascular risk with exenatide once weekly: a pooled analysis of patients with type 2 diabetes. Cardiovasc Diabetol. 2015;14:12.

10. Trujillo JM, Nuffer W, Ellis SL. GLP-1 receptor agonists: a review of head-to-head clinical studies. Ther Adv Endocrinol Metab. 2015;6(1):19-28.

11. Wolters Kluwer. Medi-Span Electronic Drug File (MED-File) v2 | Clinical Drug Information.

12. Charlson ME, Charlson RE, Peterson JC, Marinopoulos SS, Briggs WM, Hollenberg JP. The Charlson comorbidity index is adapted to predict costs of chronic disease in primary care patients. J Clin Epidemiol. 2008;61(12):1234-40.

13. Austin SR, Wong YN, Uzzo RG, Beck JR, Egleston BL. Why summary comorbidity measures such as the Charlson Comorbidity Index and Elixhauser Score work. Med Care. 2015;53(9):e65-72.

14. Sun F, Wu S, Wang J, et al. Effect of glucagon-like peptide-1 receptor agonists on lipid profiles among type 2 diabetes: a systematic review and network meta-analysis. Clin Ther. 2015;37(1):225-41.

15. Wang B, Zhong J, Lin H, et al. Blood pressure-lowering effects of GLP-1 receptor agonists exenatide and liraglutide: a meta-analysis of clinical trials. Diabetes Obes Metab. 2013;15(8):737-49.

16. Okerson T, Chilton RJ. The cardiovascular effects of GLP-1 receptor agonists. Cardiovasc Ther. 2012;30(3):e146-55. 
APPENDIX A Multivariate Logistic Regression for Patients Reaching A1c Goal <8\% and <9\% at 1 Year for Patients with Baseline Alc $\geq 7 \%$

\begin{tabular}{|c|c|c|c|c|c|c|}
\hline \multirow[b]{2}{*}{ Variable } & \multicolumn{3}{|c|}{ Likelihood of Achieving $<8 \%(n=4,321)$} & \multicolumn{3}{|c|}{ Likelihood of Achieving $<9 \%(n=4,321)$} \\
\hline & Odds Ratio & $95 \% \mathrm{CI}$ & $P$ Value & Odds Ratio & $95 \% \mathrm{CI}$ & $P$ Value \\
\hline Baseline Alc & 0.53 & 0.50 to 0.56 & $<0.001$ & 0.52 & 0.49 to 0.55 & $<0.001$ \\
\hline \multicolumn{7}{|c|}{ Baseline insulin use (ref: insulin prescribed before index date) } \\
\hline No insulin prescribed on or before index date & 1.92 & 1.44 to 2.55 & 0.000 & 1.72 & 1.25 to 2.39 & 0.001 \\
\hline Insulin newly prescribed on index date & 2.72 & 2.00 to 3.70 & $<0.001$ & 1.84 & 1.29 to 2.61 & 0.001 \\
\hline \multicolumn{7}{|l|}{ Age, years (reference: $<40$ ) } \\
\hline $40-64$ & 1.19 & 0.90 to 1.59 & 0.227 & 1.33 & 0.97 to 1.83 & 0.076 \\
\hline$\geq 65$ & 1.65 & 1.18 to 2.29 & 0.003 & 1.77 & 1.21 to 2.59 & 0.003 \\
\hline Female & 1.15 & 1.00 to 1.33 & 0.047 & 1.18 & 0.99 to 1.40 & 0.059 \\
\hline \multicolumn{7}{|l|}{ Race (reference: white) } \\
\hline Black & 0.76 & 0.58 to 1.00 & 0.050 & 1.10 & 0.80 to 1.51 & 0.560 \\
\hline Hispanic & 0.81 & 0.56 to 1.16 & 0.249 & 0.69 & 0.46 to 1.05 & 0.081 \\
\hline Other & 0.83 & 0.55 to 1.27 & 0.393 & 0.88 & 0.53 to 1.44 & 0.605 \\
\hline Unknown & 0.88 & 0.72 to 1.07 & 0.189 & 1.04 & 0.83 to 1.32 & 0.718 \\
\hline \multicolumn{7}{|l|}{ Region (reference: East) } \\
\hline South & 1.30 & 1.09 to 1.55 & 0.004 & 1.16 & 0.94 to 1.43 & 0.176 \\
\hline Midwest & 1.38 & 1.11 to 1.71 & 0.004 & 1.26 & 0.97 to 1.63 & 0.079 \\
\hline West & 1.45 & 1.12 to 1.87 & 0.005 & 1.49 & 1.09 to 2.05 & 0.013 \\
\hline \multicolumn{7}{|l|}{ Provider specialty (reference: primary care) } \\
\hline Endocrinology & 1.19 & 1.02 to 1.40 & 0.031 & 1.26 & 1.04 to 1.53 & 0.019 \\
\hline Other & 2.39 & 0.67 to 8.49 & 0.179 & 2.01 & 0.41 to 9.90 & 0.390 \\
\hline \multicolumn{7}{|l|}{ Comorbidities } \\
\hline Hypertension & 0.97 & 0.81 to 1.16 & 0.736 & 0.97 & 0.79 to 1.21 & 0.808 \\
\hline Acute MI & 1.10 & 0.47 to 2.57 & 0.835 & 0.80 & 0.29 to 2.16 & 0.657 \\
\hline Cardiovascular disease & 0.97 & 0.75 to 1.26 & 0.818 & 0.74 & 0.55 to 1.01 & 0.054 \\
\hline Cerebrovascular disease & 1.25 & 0.71 to 2.20 & 0.434 & 1.60 & 0.76 to 3.34 & 0.214 \\
\hline Kidney disease & 0.88 & 0.69 to 1.13 & 0.324 & 0.99 & 0.73 to 1.32 & 0.922 \\
\hline Hyperlipidemia & 0.94 & 0.78 to 1.14 & 0.546 & 1.03 & 0.81 to 1.30 & 0.805 \\
\hline Microvascular complications & 1.02 & 0.79 to 1.33 & 0.858 & 0.83 & 0.61 to 1.13 & 0.231 \\
\hline \multicolumn{7}{|c|}{ Other diabetes medication(s) classes prescribed before index date } \\
\hline Metformin & 0.88 & 0.65 to 1.19 & 0.407 & 0.95 & 0.68 to 1.34 & 0.773 \\
\hline Sulfonylurea & 0.54 & 0.40 to 0.71 & $<0.001$ & 0.69 & 0.50 to 0.95 & 0.021 \\
\hline TZDs & 0.90 & 0.68 to 1.20 & 0.482 & 0.78 & 0.56 to 1.07 & 0.127 \\
\hline DPP-4 & 0.82 & 0.63 to 1.08 & 0.162 & 0.96 & 0.71 to 1.31 & 0.818 \\
\hline Pramlintide & 0.79 & 0.40 to 1.54 & 0.485 & 0.69 & 0.33 to 1.46 & 0.333 \\
\hline Other OADs & 0.69 & 0.47 to 1.02 & 0.066 & 0.48 & 0.31 to 0.73 & 0.001 \\
\hline
\end{tabular}




\begin{tabular}{l|l}
\multicolumn{1}{c|}{ APPENDIX B } & \multicolumn{1}{c}{$\begin{array}{l}\text { Weight, LDL-C, and Blood Pressure } \\
\text { Outcomes Overall at } 1 \text { Year }\end{array}$} \\
\hline 1-Year Follow-up Goal Attainment & \multicolumn{1}{c}{$\begin{array}{c}\text { Overall } \\
(\mathbf{n}=5,141)\end{array}$} \\
\hline Weight (kg) & $\mathrm{n}=4,804$ \\
\hline Baseline mean (SD) & $108.0(24.8)$ \\
\hline Follow-up mean (SD) & $105.7(24.7)$ \\
\hline Mean difference (SD) & $-2.2(7.0), P<0.001$ \\
\hline LDL-C (mg/dL) & $\mathrm{n}=1,734$ \\
\hline Baseline mean (SD) & $90.1(33.8)$ \\
\hline Follow-up mean (SD) & $87.9(33.3)$ \\
\hline Mean difference (SD) & $-2.1(30.5), P=0.003$ \\
\hline LDL-C goal attainment (\%) & $\mathrm{n}=1,734$ \\
\hline Baseline $<100 \mathrm{mg} / \mathrm{dL}$ & 67.1 \\
\hline Follow-up $<100 \mathrm{mg} / \mathrm{dL}$ & $69.2, P=0.722$ \\
\hline Blood pressure goal attainment $(\%)$ & $\mathrm{n}=4,826$ \\
\hline Baseline $<140 / 90 \mathrm{mmHg}$ & 73.2 \\
\hline Follow-up $<140 / 90 \mathrm{mmHg}$ & $76.5, P<0.001$ \\
\hline Baseline $<130 / 80 \mathrm{mmHg}$ & 39.0 \\
\hline Follow-up $<130 / 80 \mathrm{mmHg}$ & $42.2, P<0.001$ \\
\hline LDL-C=low-density lipoprotein cholesterol; SD=standard deviation. \\
\hline
\end{tabular}

